\title{
INFLUÊNCIAS DE PROCESSO NO LIMITE DE ESCOAMENTO DE CANTONEIRA NA ESPECIFICAÇÃO NBR 7007 AR 415*
}

\author{
Luciana Vilarinho Ramos de Carvalho 1 \\ Jéveson Batista dos Santos ${ }^{2}$ \\ Rosan Fernandes Lima ${ }^{3}$
}

\section{Resumo}

Este trabalho tem como objetivo avaliar o efeito do nióbio e do vanádio no aço estrutural, conforme norma brasileira NBR 7007 AR 415, quando laminado a quente a diferentes temperaturas de reaquecimento, nos resultados de limite de escoamento, limite de resistência e alongamento. Os demais parâmetros de processo que influenciam as propriedades mecânicas dos aços como temperatura e taxa de deformação de cada passe, temperatura de acabamento e taxa de resfriamento foram controlados e considerados constantes. Os resultados do ensaio de tração mostraram que os limites de escoamento e resistência da corrida com vanádio foram bem superiores aos obtidos da corrida com nióbio. $\mathrm{O}$ alongamento, em contrapartida, foi reduzido na corrida com vanádio, mas acima do valor mínimo especificado pela norma. Além disso, na corrida com nióbio, foi observado aumento das tensões de escoamento e resistência com o aumento da temperatura de reaquecimento de tarugos. Esses resultados propiciam uma maior flexibilidade da usina em trabalhar com os dois tipos de liga dependendo das condições de mercado e operacionais.

Palavras-chave: Aço estrutural; Ensaio de tração; Propriedades mecânicas.

\section{PROCESS INFLUENCE ON YIELD STRENGTH OF A HOT-ROLLED ANGLE ACCORDING TO BRAZILIAN STANDARD NBR 7007 AR 415}

\section{Abstract}

This study aims to evaluate the effect of niobium and vanadium on the mechanical properties of a hot-rolled structural steel submitted to different reheating temperatures, according to Brazilian standard NBR 7007 grade AR415 specification. The other process parameters that affect the mechanical properties of steels such as temperature and strain rate for each pass, finishing temperature and cooling rate were monitored and considered constant. The results of tensile testing showed that yield strength and tensile strength of the heat with vanadium were much higher than those obtained for the heat with niobium. However, elongation was reduced in the heat with vanadium, but above the minimum specified by the standard. Furthermore, the heat with niobium, increased yield and tensile strength by increasing reheating temperatures. These results allow greater flexibility of the plant in working with both types of microalloyings depending on market and operational conditions.

Keywords: Structural steel; Tensile testing; Mechanical properties.

Engenheira de Produto, ArcelorMittal Cariacica, Cariacica, Espírito Santo, Brasil. Especialista de Produto, ArcelorMittal Cariacica, Cariacica, Espírito Santo, Brasil.

Supervisor do Laboratório Físico, ArcelorMittal Cariacica, Cariacica, Espírito Santo, Brasil.

\footnotetext{
* Contribuição técnica ao $51^{\circ}$ Seminário de Laminação - Processos e Produtos Laminados e Revestidos, 28 a 31 de outubro de 2014, Foz do Iguaçu, PR, Brasil.
} 


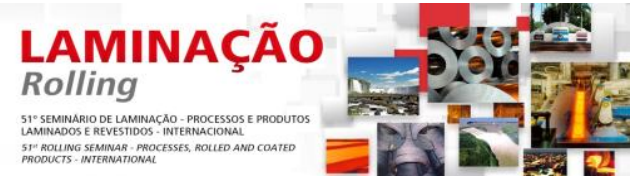

temperatura de reaquecimento de $1200^{\circ} \mathrm{C}$ apresente certa heterogeneidade de grãos.

Além disso, a temperatura de reaquecimento também irá influenciar no atraso da recristalização da austenita deformada, de acordo com a solubilidade do elemento microligante, seguido da oportunidade de precipitação durante a deformação. Desse modo, para aços com adição de $\mathrm{Nb}$, quanto maior a temperatura de reaquecimento, maior será o atraso na recristalização, pois a temperatura de deformação irá coincidir com a temperatura para precipitação dos carbonitretos de nióbio (900 a $\left.1000^{\circ} \mathrm{C}\right)$. No caso dos aços com vanádio, a elevação da temperatura de austenitização leva a um significativo atraso na recristalização somente para temperaturas de deformação abaixo de $900^{\circ} \mathrm{C}$, quando ocorre a precipitação dos carbonitretos de vanádio. Baker comenta que a altas temperaturas $\left(1200^{\circ} \mathrm{C}\right)$ vanádio em solução tem baixa influência na recristalização por arraste de soluto, mas a temperaturas mais baixas $\left(950^{\circ} \mathrm{C}\right)$ a precipitação de carbonitretos de vanádio atrasa a recristalização por travar os contornos de grão da austenita cujo processo é favorecido quando se tem alto teor de nitrogênio, e consequentemente maior fração volumétrica de precipitados de $\mathrm{V}(\mathrm{C}, \mathrm{N})[3]$.

\section{MATERIAIS E MÉTODOS}

Para a realização dos testes, foram produzidas duas corridas na Aciaria Elétrica da ArcelorMittal Cariacica, sendo uma com adição de Nb e outra com V. A composição química das corridas é mostrada na Tabela 1.

Tabela 1. Composição química das corridas (\% massa)

\begin{tabular}{ccccccccc}
\hline Corrida & $\mathrm{C}$ & $\mathrm{Mn}$ & $\mathrm{Si}$ & $\mathrm{P}$ & $\mathrm{Nb}$ & $\mathrm{V}$ & $\mathrm{Cu}$ & $\mathrm{N}$ \\
\hline $\mathrm{A}$ & 0,24 & 1,25 & 0,22 & 0,016 & 0,032 & - & 0,17 & 0,0107 \\
\hline B & 0,24 & 1,25 & 0,22 & 0,027 & - & 0,044 & 0,15 & 0,0133 \\
\hline
\end{tabular}

Segundo a norma brasileira NBR 7007 [4], a composição química dos aços de grau AR415, em análise efetuada na corrida, deve conter os teores indicados na Tabela 2 abaixo.

Tabela 2. Composição química do aço NBR 7007 grau AR415 (\%massa)

\begin{tabular}{cccccccccccc}
\hline Grau & $\mathrm{C}$ & $\mathrm{Mn}$ & $\mathrm{Si}$ & $\mathrm{P}$ & $\mathrm{S}$ & $\mathrm{Cu}$ & $\mathrm{V}$ & $\mathrm{Nb}$ & $\mathrm{Cr}$ & $\mathrm{Ni}$ & $\mathrm{Mo}$ \\
\hline \multirow{2}{*}{$\mathrm{AR415*}$} & 0,26 & 0,50 & 0,10 & 0,040 & 0,050 & 0,35 & 0,050 & 0,050 & 0,35 & 0,35 & 0,05 \\
& máx. & $\begin{array}{c}\text { a } \\
\text { 1,35 }\end{array}$ & $\begin{array}{c}0,40 \\
\text { máx. }\end{array}$ & máx. & máx. & máx. & máx. & máx. & máx. & máx.
\end{tabular}

${ }^{*} \mathrm{Nb}+\mathrm{V} \geq 0,010 \%$

A laminação dos tarugos também ocorreu na ArcelorMittal Cariacica, no Laminador Leve. A bitola utilizada nos testes foi a cantoneira de $65 \times 4 \mathrm{~mm}$. Foram objetivadas três temperaturas de reaquecimento dos tarugos: $1100^{\circ} \mathrm{C}$, usada em outros tipos de aço, $1140^{\circ} \mathrm{C}$, usada nos aços de baixo carbono e $1160^{\circ} \mathrm{C}$, para proporcionar maior dissolução dos carbonitretos. Vale destacar que o forno de reaquecimento da Linha

\footnotetext{
* Contribuição técnica ao $51^{\circ}$ Seminário de Laminação - Processos e Produtos Laminados e Revestidos, 28 a 31 de outubro de 2014, Foz do Iguaçu, PR, Brasil.
} 


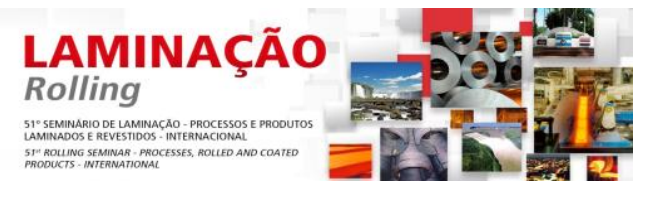

Leve é um forno do tipo empurrador, portanto temperaturas acima de $1160^{\circ} \mathrm{C}$ não são recomendadas por questões operacionais.

Os testes iniciaram com a corrida $A$ (corrida com $\mathrm{Nb}$ ) a temperatura de reaquecimento de $1100^{\circ} \mathrm{C}$. Foram laminados dez tarugos, e foram retiradas cinco amostras correspondentes aos cinco últimos tarugos laminados para ensaio de tração no Laboratório. Após a laminação desses dez tarugos, a temperatura de reaquecimento foi alterada para $1140^{\circ} \mathrm{C}$, foi feita uma separação no leito de resfriamento e após aguardar trinta minutos, mais cinco amostras correspondentes a cinco tarugos diferentes foram retiradas para o ensaio de tração. Novamente, a temperatura de reaquecimento foi modificada para $1160^{\circ} \mathrm{C}$, uma nova separação no leito foi feita e aguardado mais trinta minutos para retirada de outras cinco amostras. O mesmo procedimento foi repetido para a corrida $\mathrm{B}$ (com V).

Os testes foram realizados no mesmo dia e os demais parâmetros de processo, como velocidade de laminação, taxa de redução e taxa de resfriamento foram monitorados e considerados constantes.

Os ensaios de tração foram realizados na máquina universal de ensaio, de capacidade de 100 toneladas, da marca Tinius Olsen, com extensômetro adaptável, e software Navigator, localizada no Laboratório Físico da usina. O procedimento para execução do ensaio seguiu às determinações da norma ABNT NBR ISO 6892 [5].

\section{RESULTADOS E DISCUSSÃO}

A seguir serão apresentados os resultados obtidos dos testes experimentais, comparando o comportamento dos limites de escoamento, resistência e alongamento dos dois tipos de aços estudados, e também com os valores mínimos especificados pela norma NBR 7007. A Tabela 3 apresenta os limites de norma.

Tabela 3. Propriedades Mecânicas, segundo NBR 7007:2011

\begin{tabular}{cccc}
$\begin{array}{c}\text { Grau do } \\
\text { aço }\end{array}$ & LE (MPa) & LR (MPa) & Al (\%) \\
\hline AR415 & Mín. 415 & Mín. 520 & Mín. 16
\end{tabular}

\subsection{Propriedades Mecânicas}

A Figura 2 apresenta o efeito da temperatura de reaquecimento nas propriedades mecânicas das corridas $\mathrm{A}$ (com Nb) e B (com V).

* Contribuição técnica ao $51^{\circ}$ Seminário de Laminação - Processos e Produtos Laminados e Revestidos, 28 a 31 de outubro de 2014, Foz do Iguaçu, PR, Brasil. 


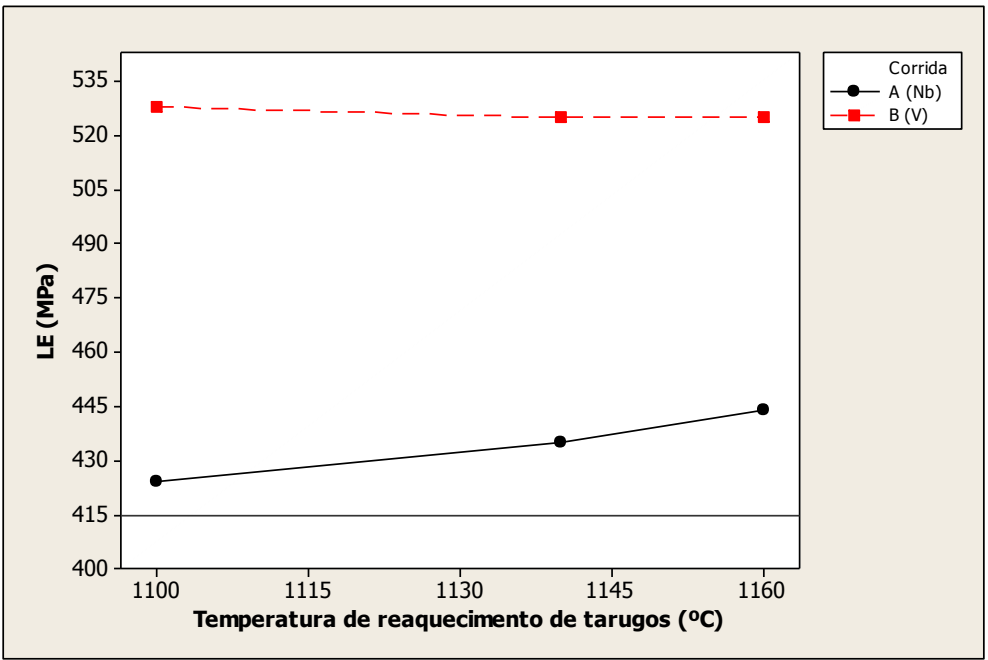

(a)

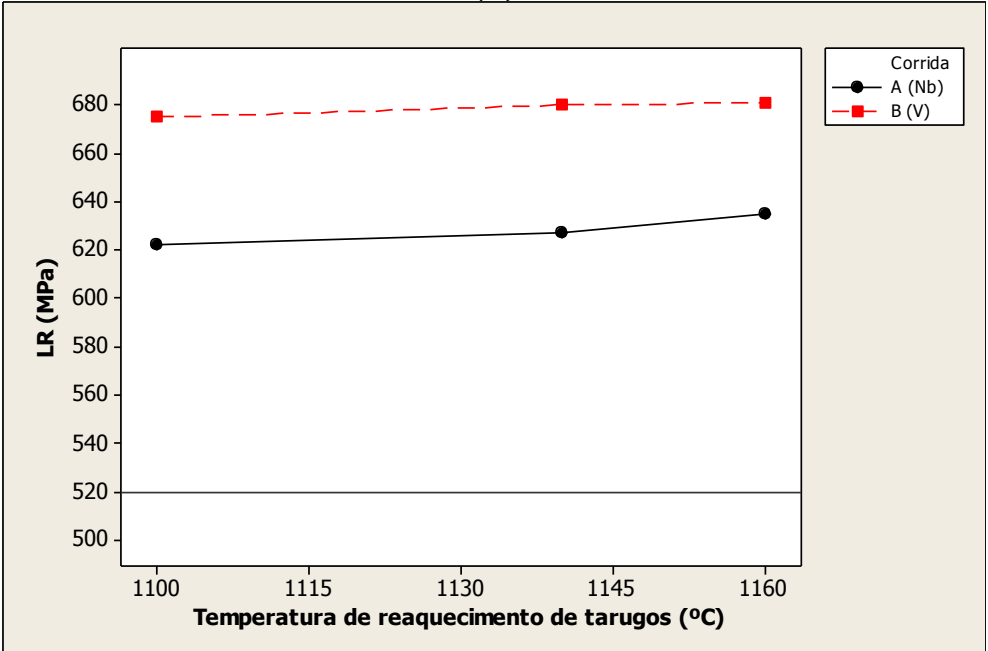

(b)

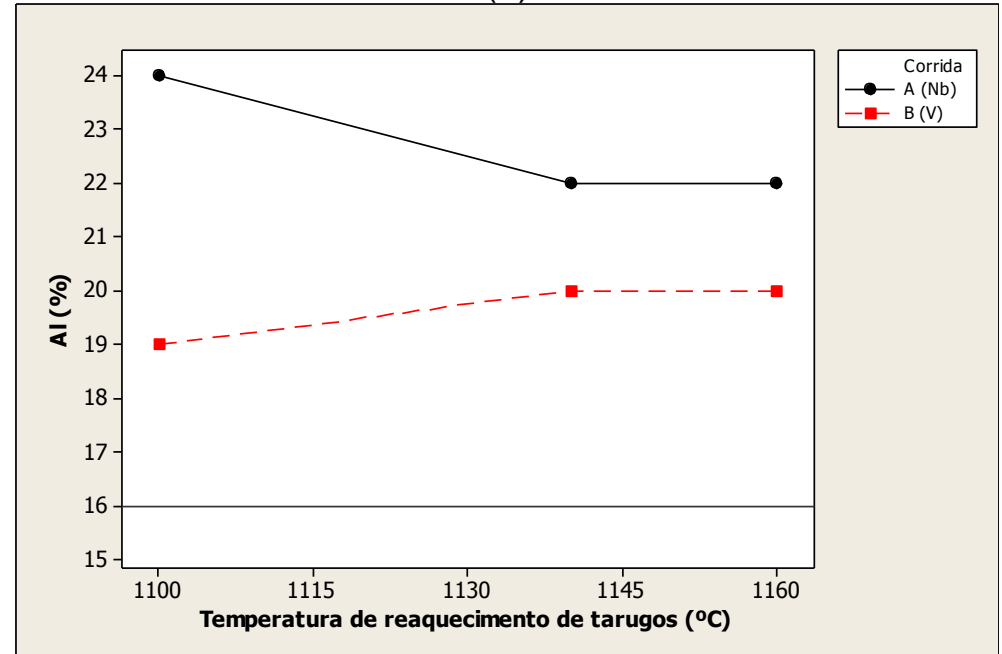

(c)

Figura 2. Efeito da temperatura de reaquecimento de tarugos (a) no limite de escoamento (b) no limite de resistência e (c) no alongamento dos aços estudados.

Os limites de escoamento e de resistência da corrida $\mathrm{A}$ (com $\mathrm{Nb}$ ) aumentaram com o aumento da temperatura de reaquecimento dos tarugos. Já o alongamento apresentou uma pequena redução com 0 aumento da temperatura de reaquecimento, como resultado do escoamento e da resistência mais altos. Apesar

* Contribuição técnica ao $51^{\circ}$ Seminário de Laminação - Processos e Produtos Laminados e Revestidos, 28 a 31 de outubro de 2014, Foz do Iguaçu, PR, Brasil. 


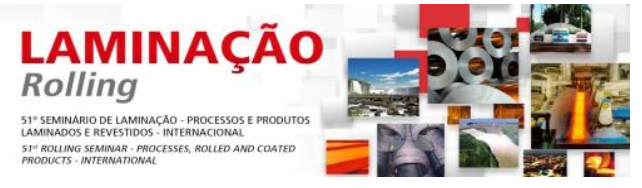

disso, o alongamento é ainda alto quando comparado com o limite mínimo estabelecido pela norma NBR 7007, que é de 16\%. Esse efeito pode ser explicado pela maior quantidade de nióbio solubilizado ao final do aquecimento o que influenciou diretamente na cinética de recristalização, no tamanho de grão recristalizado, contribuindo para o endurecimento por precipitação durante a laminação e na transformação de fase da austenita para a ferrita [6].

$\mathrm{Na}$ corrida B (corrida com V) não foi observado aumento significativo do limite de escoamento com o aumento da temperatura de reaquecimento. Entretanto, percebese um efeito inverso, onde o limite de escoamento apresentou leve redução (praticamente constante) com o incremento na temperatura, ao contrário do limite de resistência que foi levemente aumentado, levando a um aumento razoável no alongamento também.

É importante ressaltar que a corrida B (com V) apresentou resultados bem superiores de escoamento e resistência quando comparado com a corrida $A$ (com $\mathrm{Nb}$ ), em detrimento do menor alongamento. Uma possível explicação para este fato é o maior endurecimento por precipitação causado pelos carbonitretos de vanádio, que levam ao aumento na microdureza da ferrita quando comparada com o endurecimento por precipitação causado pelos carbonitretos de nióbio, conforme apresentado por Fonstein. Além disso, de modo geral, a perlita dos aços com nióbio apresentam microdureza mais baixa quando comparada aos aços com vanádio devido ao menor endurecimento por precipitação das lamelas de ferrita e devido à temperatura de início de formação de perlita ser relativamente mais alta. A Figura 3 mostra o efeito da adição dos elementos microligantes nas temperaturas de início de formação da ferrita, início e final de formação da perlita no resfriamento contínuo [2].

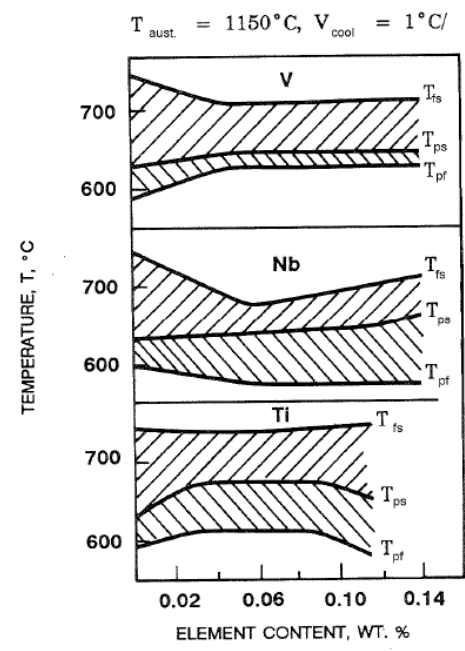

Figura 3. Efeito da adição de elementos microligantes nas temperaturas de início de formação de ferrita $\left(T_{f s}\right)$, início $\left(T_{p s}\right)$ e final ( $\left.T_{p f}\right)$ de transformação de perlita no resfriamento continuo do aço $30 \mathrm{C} 1 \mathrm{Mn} 1 \mathrm{Cr}[2]$.

De qualquer forma, comparando todos os resultados obtidos dos ensaios com os limites mínimos de propriedades mecânicas estabelecidos pela norma brasileira NBR 7007 para o grau de aço AR415 é possível notar que todos os requisitos foram plenamente atendidos. Embora, vale a ressalva de que a corrida $A$ (com $\mathrm{Nb}$ ) quando laminada a temperatura de reaquecimento de $1100^{\circ} \mathrm{C}$ apresentou um escoamento médio próximo do valor mínimo de escoamento de norma.

* Contribuição técnica ao $51^{\circ}$ Seminário de Laminação - Processos e Produtos Laminados e Revestidos, 28 a 31 de outubro de 2014, Foz do Iguaçu, PR, Brasil. 


\section{CONCLUSÃo}

A realização deste estudo permitiu concluir que o uso do nióbio não é recomendado para temperaturas de reaquecimento abaixo de $1140^{\circ} \mathrm{C}$.

A utilização do elemento vanádio no aço estrutural NBR 7007 AR415 mostrou-se uma interessante opção para obtenção das propriedades mecânicas desejadas, inclusive para temperaturas de reaquecimento na faixa de $1100^{\circ} \mathrm{C}$.

Esses resultados permitem uma flexibilidade maior para a programação da usina em função das condições de mercado, no que se refere ao consumo de ligas de $\mathrm{Nb}$ e $\mathrm{V}$ e o consumo de gás natural do forno, e também em condições operacionais diferentes das tradicionalmente utilizadas na usina de Cariacica.

\section{Agradecimentos}

Os autores agradecem à ArcelorMittal Cariacica pela oportunidade de realizar o experimento e de apresentar este trabalho.

\section{REFERÊNCIAS}

1 Niakan $\mathrm{H}$, Najafizadeh $\mathrm{A}$. Effect of niobium and rolling parameters on the mechanical properties and microstructure of dual phase steels. Materials Science \& Engineering A, 2010; 527(21):5410-5414.

2 Fonstein $\mathrm{N}$. Effects of $\mathrm{Nb}, \mathrm{V}$ and $\mathrm{Ti}$ on the evolution of structure in medium carbon steels during various hot forging steps. The Minerals, Metals \& Materials Society. 2010.

3 Baker TN. Processes, microstructure and properties of vanadium microalloyed steels. Materials Science and Technology, 2009; 25(9):1083-1107.

4 Associação Brasileira de Normas Técnicas, Rio de Janeiro. NBR 7007, Aços-carbono e microligados para barras e perfis laminados a quente para uso estrutural, 2011.10p.

5 Associação Brasileira de Normas Técnicas, Rio de Janeiro. NBR ISO 6892, Materiais Metálicos - Ensaios de tração à temperatura ambiente, 2002. 34p.

6 Reis EG. Modelo matemático para previsão das propriedades mecânicas na laminação a quente de perfis estruturais [dissertação de mestrado]. Belo Horizonte: Universidade Federal de Minas Gerais; 2007.

* Contribuição técnica ao $51^{\circ}$ Seminário de Laminação - Processos e Produtos Laminados e Revestidos, 28 a 31 de outubro de 2014, Foz do Iguaçu, PR, Brasil. 